\title{
POSISI PEREMPUAN KOTA CIREBON DI TINGKAT NASIONAL \\ DAN JAWA BARAT
}

\author{
Sriwulan Ferindian Falatehan ${ }^{1}$, \\ Maemunah \\ Institut Pertanian Bogor, \\ Universitas Nahdlatul Ulama Cirebon \\ Email : sriwulanferindian@apps.ipb.ac.id \\ mayy60@yahoo.co.id
}

\begin{abstract}
The gender equality is included in one of human rights as a human being. The right to live respectfully, free from fear can also be free to make choices in life. All of these rights are not only intended for men, but also have the same rights as men. As a result of the need to support the family and the increasing level of education of women, the emergence of the issue of gender inequality began to be voiced in Indonesia since the 1960s. This issue became part of the phenomena and dynamics of Indonesian society that made women's position more equal to men. This study intended to determine the condition and position of women in the city of Cirebon, weaknesses and strengths in the IPM (Human Development Index), IDG (Gender Empowerment Index), and IPG (Gender Development Index). This study uses the Normative Juridical approach, which is research with an approach that is more emphasized on secondary data in the form of primary, secondary or tertiary legal materials. Until now, the city of Cirebon in the empowerment of women shows quite successful achievements, namely rank 5 for IPM, rank 3 for IDG, and rank 3 for IPG at the level of West Java Province.
\end{abstract}

\section{Keywords: Position of Women and Men, Gender Equality, Women of Cirebon City}

\section{PENDAHULUAN}

Perkembangan Kota Cirebon cukup pesat, dapat dilihat dari fasilitas-fasilitas umum, hotel-hotel, kuliner, pariwisata, pusat pertokoan dan pusat perdagangan cukup ramai, hal tersebut berdampak kepada perkembangan berbagai bidang kehidupan lainnya oleh karena itu, dalam tingkat perkembangan pembangunan yang begitu pesat bagaimana perbandingan posisi perempuan di kota Cirebon dibanding dengan kabupaten Kota lain di Jawa Barat, dan bicara Perempuan pasti akan bicara tentang kesetaraan gender.

Kesetaraan gender termasuk ke dalam salah satu hak asasi sebagai manusia. Hak untuk dapat hidup secara terhormat, terbebas dari rasa ketakutan juga dapat bebas untuk menentukan pilihan hidup, segala hak-hak tersebut tidak hanya diperuntukan bagi para kaum laki-laki saja, akan tetapi pada hakikatnya perempuan pun mempunyai hak yang

\footnotetext{
${ }^{1}$ Dosen dan Peneliti Pusat Kajian Gender dan Anak IPB University.
} 
sama dengan laki-laki. Sampai saat ini, posisi perempuan seringkali dianggap sebagai mahluk yang lemah dan derajatnya berada dibawah laki-laki. Hal ini disebabkan karena persepsi sebagian masyarakat kita tentang perempuan yang masih menganggap perempuan dan laki-laki tidak sejajar, di Negara Indonesia kesetaraan antara perempuan dan laki-laki mendapatkan dukungan dan perhatian serius dari berbagai kalangan, khususnya kaum yang menamakan diri mereka feminis dan pemerhati wanita. Ditengah gerakan feminisme sebagai akibat dari kebutuhan untuk menghidupi keluarga dan semakin meningkatnya tingkat pendidikan kaum perempuan, maka munculnya isu ketidakadilan gender mulai disuarakan di Indonesia sejak 1960-an isu ini menjadi bagian dari fenomena dan dinamika masyarakat Indonesia yang membuat posisi perempuan semakin sejajar dengan laki-laki. Pandangan yang telah mengakar dan membudaya adalah setinggi-tingginya perempuan sekolah, akan kedapur juga sudah mulai dipersoalkan. Terlebih lagi dengan banyaknya posisi pekerjaan yang biasanya diduduki oleh laki-laki sekarang dapat diduduki oleh perempuan. Pergeseran tersebut merubah peran perempuan dari hanya sebatas bekerja di dapur, sumur, mengurus keluarga dan anak mejadi sejajar dengan laki-laki.

Gender jika diperumpamakan adalah misalnya jika ada kegiatan yang berkaitan dengan gender pasti, kata-kata yang muncul adalah ini sih ibu A, ini yang harus hadir Ibu B, terus yang seharusnya seperti apa. gender tidak dimaknai sebagai perbedaan fisik antara laki-laki dan perempuan dalam arti biologis. Pemaknaan gender pada perbedaan peran lakilaki dan perempuan, perilaku, yang dikonstruksikan secara sosial. Kesetaraan Gender adalah kesamaan kondisi bagi perempuan dan laki-laki untuk memperoleh kesempatan dan mendapatkan hak-haknya sebagai manusia, agar mampu berperan dan berpartisipasi dalam kegiatan politik, ekonomi, sosial budaya, pertahanan dan keamanan, dan kesamaan dalam menikmati hasil pembangunan. Kesetaraan gender dapat dicapai dengan meningkatkan pelibatan perempuan dalam proses pembangunan, sejak menyusun perencanaan, melaksanakan pembangunan, memantau jalannya pembangunan sampai mendapatkan manfaat dari program pembangunan tersebut.

Dalam mengukur kesetaraan gender tersebut, ada 3 indeks yang digunakan yaitu IPM, IPG, dan IDG. Indeks Pembangunan Manusia (IPM) merupakan ukuran kualitas hidup manusia dalam bidang kesehatan, pendidikan, maupun ekonomi. Ukuran tersebut kemudian digunakan untuk mengukur Indeks Pembangunan Gender (IPG) yang difokuskan pada faktor ketidaksetaraan antara laki-laki dan perempuan di berbagai level. Sedangkan Indeks Pemberdayaan Gender (IDG) mengukur partisipasi aktif perempuan 
pada kegiatan ekonomi yaitu dengan indikator persentase sumbangan perempuan dalam pendapatan kerja, kegiatan politik dengan indikator keterlibatan perempuan di parlemen, serta dalam pengambilan keputusan melalui indikator perempuan sebagai tenaga manajer, professional, administrasi, teknisi. Kesimpulannya, IDG digunakan untuk melihat sejauh mana pencapaian kapabilitas perempuan dalam berbagai bidang kehidupan ${ }^{2}$.

\section{METODE}

Untuk dapat mendeskripsikan, mengkaji dan menganalisa, penulis menggunakan literatus bacaan tentang perempuan, pemberdayaan perempuan dan data dari Kementrian Pemberdayaan Perempuan, Kota Cirebon dalam angka serta data yang bersumber dari Badan Pusat Statistik Kota Cirebon. Dengan menggunakan data dan informasi dari berbagai sumber, penulis mendeskripsikan, mengkaji dan menganalisa serta menyimpulkan untuk memberikan saran program dan kegiatan yang tepat untuk dilakukan di Kota Cirebon dengan kondisi yang ada. Penelitian ini bertujuan untuk: mengetahui kondisi dan posisi perempuan di Kota Cirebon, kekurangan dan kelebihan dalam IPM, IDG dan IPG. Manfaat Penelitian: Fokus lokasi adalah di Kota Cirebon, Kota Cirebon sebagai kota kecil dan kota perbatasan yang terdiri dari berbagai suku, dalam melakukan program dan kegiatan pasti ada nilai minus dan plus nya. Dengan kajian ini akan lebih terarah dalam memilih program-program dan kegiatan dalam peningkatan pemberdayaaan perempuan.

Penelitian ini menggunakan metode pendekatan Yuridis Normatif, yaitu penelitian dengan pendekatan yang lebih ditekankan pada data-data sekunder berupa bahan-bahan hukum primer, sekunder maupun tersier. Pada penelitian hukum normatif, bahan pustaka merupakan data dasar dalam (ilmu) penelitian yang digolongkan sebagai data sekunder ${ }^{3}$.

\section{HASIL DAN PEMBAHASAN}

\section{A. Pembahasan akan mencakup Indeks Pembangunan Manusia, Indeks Pemberdayaan manusia dan Indeks Pembangunan Manusia, sebagai berikut :}

\section{a. Indeks Pembangunan Manusia:}

\footnotetext{
2 Kemenpp, Pembanguna Manusia Berbasis Gender, 2018.

3 Soerjono Soekanto dan Sri Maudji, Penelitian Hukum Normatif Suatu Tinjauan Singkat, Jakarta: Raja Grafindo Persada, 1985, hlm. 24.
} 
Indeks Pembangunan Manusia (IPM) atau Human Development Index (HDI) adalah pengukuran perbandingan dari harapn hidup,melek hurup,pendidikan dan standar hidup untuk semua negara di seluruh dunia ${ }^{4}$.

IPM digunakan untuk mengklasifikasikan apakah sebuah negara adalah negara maju, negara berkembang atau negara terbelakang dan juga untuk mengukur pengaruh dari kebijakan ekonomi terhadap kualitas hidup ${ }^{5}$.

Unsur-unsur apa saja yang tercantum dalam Indeks Pembangunan manusia :

1) Angka harapan hidup, yakni perkiraan rata-rata tambahan umur seseorang yang diharapkan dapat terus hidup, atau dapat didefinisikan sebagai rata- rata jumlah tahun yang dijalani oleh seseorang setelah orang tersebut mencapai ulang tahun yang ke x. Ukuran yang lazim digunakan adalah angka harapan hidup saat lahir yang mencerminkan kondisi kesehatan pada saat itu, sehingga apabila membicarakan angka harapn hidup, adalah rata-rata jumlah tahun yang akan dijalani oleh seseorang sejak orang tersebut lahir ${ }^{6}$.

Konsep definisi Angka harapan hidup, rata-rata tahun hidup yang masih akan dijaklani oleh seseorang yang telah berhasil mencapai umur $\mathrm{x}$, pada suatu tahun tertentu, dalam situasi mortalitas yang berlaku di lingkungan masyarakatnya.

Idealnya angka harapan hidup dihitung berdasarkan angka kematian menurut umur yang datanya diperoleh dari catatan registrasi kematian secara bertahuntahun sehingga memungkinkan dibuat tabel kematian

Keguanaan AHH. Merupakan alat unruk mengevaluasi kinerja pemerintah dalam meningkatkan kesejahteraan penduduk pada umumnya, dan menbgkatkan derajat kesejatan pada khusunya. Angka harapan hidup yang rendah disuatu daertah harus dikiuti dengan program pembanguna kesehatan, dan program sosial lainnya termasuk kesehatan lingkungan, kecukupan gizi dan kaloro termasuk progam pengentasan kemiskinanan ${ }^{7}$.

\footnotetext{
${ }^{4}$ Wikipedia, Indeks Pembangunan Manusia, https://id.wikipedia.org/wiki/Indeks_Pembangunan_Manusia, diakses pada 20 Januari 2020.

5 Ibid,

${ }^{6}$ Lokadata, Angka Harapan Hidup dan Rasio Ketergantungan warga Jakarta, https://lokadata.beritagar .id/chart/preview/angka-harapan-hidup-dan-rasio-ketergantungan-warga-jakarta-1486721802, diakses pada 21 Januari 2020.

${ }^{7}$ Badan Pusat Statistik, Angka Harapan Hidup, https://sirusa.bps.go.id/sirusa/index.php/indikator/48, diakses pada 21 Januari 2020.
} 
2) Harapan lama sekolah :

Harapan lama sekolah didefinisikan sebagai lamanya sekolah (dalam tahun) yang diharapkan akan dirasakan oleh anak pada umur tertentu di masa yang akan datang ${ }^{8}$.

Kegunaan : HLS dapat digunakan untuk nengetahui kondisi pembangunan sistem pendidikan di berbagai jenjang.

3) Rata-rata lama sekolah :

Rata-rata lama sekolah (RLS) didefinikan sebagai jumlah tahun yang akan digunakan oleh penduduik dalam menjalanani pendidikan formal ${ }^{9}$. Kegunaan dapat diguakan untuk mengetahui kualitas pendidikan masyarakat dalam suatu wilayah ${ }^{10}$.

4) Pengeluaran perkapita :

Pengeluaran perkapita adalah biaya yang dikeluarkan untuk konsumsi semua anggota rumah tangga selama sebulan dibagi dengan banyaknya anggota rumah tangga ${ }^{11}$.

Kegunaan data pengeluaran dapat mengungkap tentang pola konsumsi rumah tangga secara umum menggunakan indikator proporsi pengeluaran untuk makanan dan non makanan. Komposisi pengeluaran rumah tangga dapat dijadikan ukuran untuk menilai tingkat kesejahteraan ekonomi penduduk, makin rendah presentasi pengeluaran untuk makanan terhadap total pengeluaran makin membaik tingkat kesejahteraan ${ }^{12}$.

\section{b. Indeks Pembangunan Gender (IPG)}

Digunakan untuk mengukur pencapaian dimensi dan variabel yang sama seperti IPM, tetapi mengungkap ketidakadilan pencapaian laki- laki dan perempuan, semakin mendekati angka 100 maka kesenjangan pembangunan antara perempuan dan laki-laki semakin kecil.

komponen didalamnya mencakup :

a) umur harapan hidup

\footnotetext{
8 Ibid,

9 Ibid,

${ }^{10} \mathrm{Ibid}$,

${ }^{11}$ Ibid,

${ }^{12}$ Ibid,
} 

b) harapan lama sekolah
c) rata- tara lama sekolah
d) pengeluaran perkapita.

\section{c. Indeks Pemberdayaan Gender (IDG)}

Indeks pemberdayaan gender (IDG) memperlihatkan sejauh mana kesetaraan gender dalam hal peran aktif perempuan dalam kehidupan dinia politik, pengambilan keputisan dan ekonomi. Peran aktif perempuan . Indikator ini menunjukan apakah perempuan dapat memainkan peranan aktif dalam kehidupan ekonomi dan politik.

Komponen didalam nya mencakup :

1) Keterlibatan perempuan di parlemen

Untuk meningkatkan partisipasi perempuan dalam politik dilakukan dengan ditetapkannya Undang-undang No 10 Tahun 2008. Dalam UU tersebut, dijelaskan bahwa sekurang-kurangnya harus ada 30 persen keterwakilan perempuan pada kepengurusan partai politik tingkat pusat dan bakal calon anggota DPR/DPRD lembaga legislatif. Meski belum mampu memenuhi target yang diharapkan, tapi dengan tren keterwakilan perempuan di parlemen yang cenderung meningkat telah menimbulkan optimisme bahwa peran perempuan di bidang politik semakin nyata terlihat dan berpotensi untuk terus ditingkatkan.

2) Perempuan sebagai tenaga manajer, profesional, adminstrasi, teknisi

Kaum wanita masih ada yang menganggap bahwa, wanita kaum lemah yang selalu butuh perlindungan laki- laki. Maka nya masih ada yang menganggap bahwa wanita tidak layak jadi pemimpin. Dengan alasan bahwa laki- laki langkahnya panjang, pikirannya luas, laki- laki lebih kuat, lebih rasional dan lebih bijak, hal itulah kemungkinan yang menyebabkan perempuan dalam halhal kepemimpinan masih tertinggal. Namun saat ini sudah banyak kaum wanita yang menjadi manajer, tenaga profesional dan tenaga teknisi, yang dahuulu masih sangat langka.

3) Sumbangan perempuan dalam pendapatan kerja.

Kesenjangan capaian antara laki-laki dan perempuan di pasar tenaga kerja merupakan fenomena yang umum terjadi terutama di negara-negara 
berkembang. Perbedaan upah yang diterima menjadi salah satu hal yang paling sering terjadi. Kesenjangan dalam upah pada akhirnya berimbas pada munculnya kesenjangan dalam sumbangan pendapatan kaum perempuan.

\section{B. Hasil Kajian Perempuan Kota Cirebon Berdasarkan Data Kemenpp Tahun 2019 a. Indeks Pembangunan Manusia (IPM)}

Indeks Pembangunan Manusia Nasional Tahun 2019 ada pada angka 71,39 tertinggi propinsi DKI Jakarta yakni 80,47, dan terendah Papua yakni 60,06. Sedangkan Jawa Barat ada pada posisi 10 dengan angka 71,30, Jawa Barat mengalami kenaikan yang begitu signifikan dari ranking 17 ke ranking 10 .

Indeks Pembangunan Manusia Kota Cirebon untuk IPM Laki-laki ada di peringkat 8, dengan angka 77,95, tertinggi Kota Bekasi dengan angka 85,56 dan terendah kabupaten Cianjur 69,24, sedangka untuk IPM Perempuan berada pada rangking 5 dengan angka 73,23, tertinggi Kota bandung dengan angka 80,20, dan terendah Bandung Barat dengan angka 57,41 .

Dengan angka masing-masing komponen adalah sebagai berikut :

\begin{tabular}{|c|l|c|c|}
\hline No & \multicolumn{1}{|c|}{ Uraian } & Laki- Laki & Perempuan \\
\hline 1 & Umur Harapan Hidup (UHH) & 70,00 & 73,87 \\
\hline 2 & Harapan Lama Sekolah (HLS) & 12,77 & 13,38 \\
\hline 3 & Rata-Rata Lama Sekolah (RLS) & 10,43 & 9,31 \\
\hline 4 & Pengeluaran Perkapita (PP) & 15,484 & 10,993 \\
\hline
\end{tabular}

Sumber : KemenPP

Data diatas menunjukan ada beberapa komponen dimana perempuan ada di posisi atas, yakni untuk umur harapan hidup dan harapan lama sekolah, begitu juga ada yang berada diposisi di bawah yakni rata-rata lama sekolah dengan pengeluaran perkapita.

\section{b. Indeks Pembangunan Gender (IPG)}

Indeks Pembangunan Gender, merupakan bilangan atau angka IPM yang terpilah antara laki- dan perempuan. Berikut data IPG berdasarkan kajian dari KemenPP tahun 2019 IPG Nasional : 90,99, Jawa Barat berada di angka 89,19 dengan peringkat 23, Kota Cirebon berada di angka 93,94 peringkat 3, Kota Bandung 95,11 sebagai Kota/Kabupaten tertinggi dan Bandung Barat 79,18 berada pada posisi terakhir. 
Dengan angka masing-masing sebagai berikut :

\begin{tabular}{|c|l|c|c|c|c|c|c|c|c|c|c|c|}
\hline No & Uraian & \multicolumn{2}{|c|}{ UHH } & \multicolumn{2}{c|}{ HLS } & \multicolumn{2}{c|}{ RLS } & \multicolumn{2}{c|}{ P. Perkapita } & \multicolumn{2}{|c|}{ IPM } & IPG \\
\hline & & L & $\mathbf{P}$ & $\mathbf{L}$ & $\mathbf{P}$ & $\mathbf{L}$ & $\mathbf{P}$ & $\mathbf{L}$ & $\mathbf{P}$ & $\mathbf{L}$ & $\mathbf{P}$ & \\
\hline 1 & $\begin{array}{l}\text { JAWA } \\
\text { BARAT }\end{array}$ & 70,76 & 74,62 & 12,44 & 12,52 & 8,60 & 7,71 & 15.258 & 7.905 & 75,49 & 67.33 & 89,19 \\
\hline 2 & $\begin{array}{l}\text { KOTA } \\
\text { CIREBON }\end{array}$ & 70,00 & 73,87 & 12,77 & 13,38 & 10,43 & 9,31 & 15,484 & 10,933 & 77,95 & 73,23 & 93,94 \\
\hline 3 & $\begin{array}{l}\text { KOTA } \\
\text { BANDUNG }\end{array}$ & 72,07 & 75,93 & 14,16 & 14,43 & 10,91 & 10,34 & 22,072 & 15,833 & 84,32 & 80,20 & 95,11 \\
\hline 4 & $\begin{array}{l}\text { BANDUNG } \\
\text { BARAT }\end{array}$ & 70,04 & 73,92 & 11,87 & 11,82 & 8,39 & 7,65 & 12,679 & 3,854 & 72,51 & 57,41 & 79,18 \\
\hline
\end{tabular}

Sumber : KemenPP

Data diatas mengambarkan :

1) Angka Jawa Barat, Kab/Kota Tertinggi yakni Kota Bandung, Kabupaten terendah yakni Kabupaten Bandung Barat.

2) Dari data terlihat bahwa posisi Kota Cirebon dibanding Propinsi Jawa Barat, : untuk Umur Harapan Hidup laki - laki dan Perempuan ada dibawah Propinsi Jawa Barat, Harapan Lama Sekolah ada diatas Jawa Barat. Rata - rata Lama Sekolah ada diatas Jawa Barat, pengeluaran Perkapita juga ada diatas Jawa Barat.

3) Kota Cirebon Harapan Lama Sekolah berada diatas Jawa Barat dan Kabupaten Bandung Barat, Rata- rata lama sekolah ada diatas Jawa Barat dan Bandung Barat, begitu juga Pengeluaran Perkapita ada di atas Jawa Barat dan Kabupaten Bandung Barat.

4) Kemudian di bandingkan dengan Kota Bandung dengan posisi tertinggi di Jawa barat, semua komponen ada dibawah Kota Bandung. Bila dibanding dengan Bandung Barat, hanya Umur Harapan Hidup yang Bandung Barat lebih tinggi dari Kota Cirebon

\section{c. Indeks Pemberdayaan Gender (IDG)}

Kota Cirebon penduduk tida kurang dari 350.000 jiwa, mempunyai 35 anggota DPRD, dan anggota DPRD perempuan 10 orang, artinya sudah mencapai 28,57 \%, ini merupakan prestasi untuk Kota Cirebon dalam pelibatan perempuan di parlemen, selanjutnya bagaimana untuk Jawa Barat, Jawa Barat sejumlah 120 anggota di dominasi oleh kaum laki-laki, 23 anggota perempuan atau 19,16 Persen dan 97 orang laki-laki. 


\begin{tabular}{|c|l|c|c|}
\hline NO & \multicolumn{1}{|c|}{ URAIAN } & JML PNS & JABATAN \\
\hline 1 & Jumlah PNS & 4.828 & 683 \\
\hline 2 & Laki- Laki & 2.196 & 420 \\
\hline 3 & Perempuan & 2.632 & 263 \\
\hline
\end{tabular}

Sumber data : Badan Kepegawaian, Pendidikan dan Pelatihan Daerah Kota Cirebon

Pegawai Negeri Sipil di Kota Cirebon sejumlah 4.828, terdiri dari laki- laki 2.196 dan perempuan 2.632 orang, yang menduduki jabatan terdiri dari laki- laki 420 perempuan 263 orang. Data tersebut belum membandingkan dengan jabatan fungsional dan non fungsional, namun dari data tersebut kaum perempuan yang menempati jabatan 39,66\% dan sisanya kaum laki-laki.

Kodisi IDG dibanding dengan Kabupaten/Kota lain di Jawa Barat dan capaian tingkat nasional.

\begin{tabular}{|c|l|c|c|c|c|}
\hline NO & \multicolumn{1}{|c|}{ KAB/KOTA } & $\begin{array}{c}\text { PEREMPUAN } \\
\text { DI } \\
\text { PARLEMEN }\end{array}$ & $\begin{array}{c}\text { PEREMPUAN } \\
\text { SBG TENAGA } \\
\text { PROF }\end{array}$ & $\begin{array}{c}\text { SUMBANGAN } \\
\text { PENDAPATAN } \\
\text { PEREMPUAN }\end{array}$ & IDG \\
\hline 1 & NASIONAL & 17,32 & 47,02 & 36,70 & 72,10 \\
\hline 2 & JAWA BARAT & 22,00 & 41,38 & 29,51 & 70,20 \\
\hline 3 & KOTA DEPOK & 38,00 & 44,16 & 32,02 & 81,49 \\
\hline 4 & KOTA CIREBON & 22,86 & 48,24 & 32,01 & 73,97 \\
\hline 5 & SUKABUMI & 12,00 & 27,84 & 27,12 & 53,07 \\
\hline
\end{tabular}

Data diatas menunjukan Jawa Barat ada dibawah nasional, rangking di Jawa Barat adalah kota Depok, Kota Cirebon ada di rangking 3, dan terendah adalah kabupaten Sukabumi. Dari data diatas :

1. Dibanding dengan capaian Nasional Kota Cirebon :

- Perempuan di Parlemen ada diatas capaian nasional

- Perepmpuan sebagai tenaga profesional ada di atas capaian nasional

- Sumbangan pendapatan perempuan ada dibawah nasional

- Secara keseluruhan IDG Kota Cirebon diatas capaian nasional

2. Dibanding dengan capaian Jawa Barat :

- Perempuan di Parlemen ada diatas capaian Propinsi Jawa Barat

- Perepmpuan sebagai tenaga profesional ada di atas capaian Propinsi Jawa Barat

- Sumbangan pendapatan perempuan ada diatas Propinsi Jawa Barat

- Secara keseluruhan IDG Kota Cirebon diatas capaian nasional 
3. Dibanding dengan capaian Kota Depok sebagai ranking tertinggi di Jawa Barat :

- Perempuan di Parlemen ada dibawah capaian kota depok

- Perepmpuan sebagai tenaga profesional ada di atas capaian kota Depok

- Sumbangan pendapatan perempuan ada dibawah capaian kota Depok

4. Dalam komponen perempuan diparlemen masih menggunakan data akhir periode 2014-2019, saat ini perempuan di perlemen 28,57\% dengan 10 anggota DPRD.

Dengan tingginya angka perempuan di Parlemen diharapkan kebijakan - kebijakan akan berpihak kepada kesetaraan gender.

\section{d. Pilihan Program Pemberdayaan Perempuan Yang Lebih Tepat Dilakukan}

Dari data IPM-IPG dan IDG Kota Cirebon berada pada 10 besar di tingkat Jawa Barat, yakni :

1. IPM berada pada ranking ke 8 untuk laki-laki dan ranking 5 untuk perempuan

2. IPG berada pada ranking ke 3

3. IDG berada pada ranking ke 3

Untuk memacu agar Perempuan Kota Cirebon sejajar dengan kota-kota yang lebih maju seperti Kota Bandung dan Kota Depok, maka dalam pemberdayaan perempuan agar melakukan kegiatan-kegiatan untuk meningkatkan komponen-komponen yang masih rendah, yakni :

1. Rata-rata lama sekolah yang berada pada angka 9,31, sedangkan Kota Bandung 10,34

2. Pengeluaran perkapita 10, 93 dan Kota Bandung 15, 833.

3. Sumbangan perempuan untuk pendapatan Kota Cirebon dan Kota Depok beda sangat kecil, yakni 32, 01 dan 32,02

Program dan kegiatan yang disarankan untuk meningkatkan komponen-komponen yang masih rendah adalah :

1. Meningkatkan dan mempertahankan peran perempuan dalam parlemen, yang sekarang sudah 28,57 melalui pengkaderan, pendidikan politik 
2. Meningkatkan mutu pendidikan anak usia dini

3. Mencegah drop out SD, SMP dan SMA

4. Mendorong anak untuk melanjutkan sekolah ke jenjang yang lebih tinggi, dan sejak dalam pendidikan usia dini sudah mempunyai keinginan untuk mencapai pendidikan yang lebih tinggi.

5. Mendukung kedudukan perempuan pada jabatan-jabatan strategis,

6. Mendorong balai latihan kerja untuk melatih dan uji kompetensi, agar perempuan menjadi tenaga profesional

7. Mendorong dan memfasilitasi perempuan yang melakukan ekonomi produktif, melalui pendampingan sampai mandiri, kemudahan akses perijinan dan pendampingan dalam pemasaran pemasaran.

8. Bea siswa di Perguruan Tinggi bagi perempuan-perempuan yang punya bakat minat untuk melanjutkan kuliah.

9. Membantu organissai- organisai perempuan bidang usaha ekonomi produktif,

10. Pengadaan petugas pendamping pengusaha perempuan pemula berusaha.

11. Pendampingan oleh Perguruan Tinggi, dalam bidang usaha ekonomi produktif perempuan pengusaha pemula.

12. Melakukan pengendalian terhadap pertumbuhan penduduk

\section{PENUTUP}

\subsection{Simpulan}

1. Kota Cirebon sampai saat ini dalam pemberdayaan Perempuan menunjukan capaian yang cukup berhasil, yakni ranking 5 untuk IPM, IDG ranking 3 dan IPG ranking 3 di tingkat Propinsi Jawa Barat.

2. Beberapa kompnen yang masih rendah bila dibanding dengan kabupaten /Kota lain yakni : rata-rata lama sekolah, pengeluaran perkapita, dan sumbangan perempuan untjuk pendapatan.

\subsection{Saran}

1. Lakukan sosialisasi tentang pemberdayaan perempuan bukan hanya oleh pemerintah, tapi dilakukan sejak kecil dalam keluarga dan Pendidikan Usia Dini. Program yang dilakukan bersifat kontinyu, evaluasi perlu dilakukan, dan pendampingan dalam program-program yang baru. 
2. Perlunya kesinambungan dalam melaksanakan program, pendampingan bagi pengusaha perempuan pemula, sampai mandiri dan melibatkan Perguruan Tinggi serta pihak swasta dan Perlu diprioritaskan beasiswa bagi perempuan yang punya minat dan bakat.

\section{DAFTAR PUSTAKA}

Badan Pusat Statistik, Angka Harapan Hidup, https://sirusa.bps.go.id /sirusa/index.php/indikator/48, diakses pada 21 Januari 2020.

Data Badan Kepegawaian, Pendidikan dan Pelatihan Daerah Kota Cirebon

Data Badan Pusat Statistik Kota Cirebon.

Soerjono Soekanto dan Sri Maudji, Penelitian Hukum Normatif Suatu Tinjauan Singkat, Jakarta: Raja Grafindo Persada, 1985, hlm 24

Kajian dan Analisa tentang Pembanguna Manusia berbasis Gender, KemenPP 2019.

Kemenpp, Pembanguna Manusia Berbasis Gender, 2018.

Lokadata, Angka Harapan Hidup dan Rasio Ketergantungan warga Jakarta, https://lokadata.beritagar .id/chart/preview/angka-harapan-hidup-dan-rasioketergantungan-warga-jakarta-1486721802, diakses pada 21 Januari 2020.

Wikipedia, Indeks Pembangunan Manusia, https://id.wikipedia.org/wiki/Indeks PembangunanManusia, diakses pada 20 Januari 2020. 